\title{
Influence of type-4 dipeptidyl peptidase inhibition on endothelium-dependent relaxation of aortae from a db/db mouse model of type 2 diabetes: $a$ comparison with the effect of glimepiride
}

This article was published in the following Dove Press journal:

Diabetes, Metabolic Syndrome and Obesity: Targets and Therapy

\author{
Owen L Woodman (1) \\ Jacinta M Ortega' \\ Joanne L Hart' \\ Thomas Klein ${ }^{2}$ \\ Simon Potocnik' \\ 'School of Health and Biomedical \\ Sciences, RMIT University, Bundoora, \\ VIC, Australia; ${ }^{2}$ Department of \\ Cardiometabolic Diseases Research, \\ Boehringer Ingelheim Pharma, Biberach, \\ Germany
}

Purpose: The aim of this study was to investigate the effects of the type- 4 dipeptidyl peptidase (DPP-4) inhibitors linagliptin and vildagliptin as well as the sulfonylurea glimepiride on endothelium-dependent relaxation of aortae from female $\mathrm{db} / \mathrm{db}$ mice with established hyperglycemia to determine whether these treatments were able to attenuate diabetes-induced endothelial dysfunction.

Materials and methods: The mice were treated with glimepiride $(2 \mathrm{mg} / \mathrm{kg}$ po per day, weeks $1-6, \mathrm{n}=12$ ), glimepiride plus vildagliptin (glimepiride $2 \mathrm{mg} / \mathrm{kg}$ po per day, weeks $1-6$; vildagliptin $3 \mathrm{mg} / \mathrm{kg}$ po per day, weeks 4-6, n=11), glimepiride plus linagliptin (glimepiride 2 $\mathrm{mg} / \mathrm{kg}$ po per day, weeks 1-6; linagliptin $3 \mathrm{mg} / \mathrm{kg}$ po per day, weeks $4-6, \mathrm{n}=11$ ) or linagliptin $(3 \mathrm{mg} / \mathrm{kg}$ po per day, weeks $1-6, \mathrm{n}=12$ ). Endothelium-dependent relaxation using acetylcholine was assessed in the absence and presence of pharmacological tools (TRAM-34 $1 \mu \mathrm{M}$; apamin 1 $\mu \mathrm{M}$; N-nitro-L-arginine [L-NNA] $100 \mu \mathrm{M} ; 1 \mathrm{H}$-[1,2,4] oxadiazolo [4,3-a]quinoxalin-1-one [ODQ] $10 \mu \mathrm{M})$ to distinguish relaxation mediated by nitric oxide (NO).

Results: Linagliptin was associated with a significant improvement in endothelium-dependent relaxation (ACh Rmax; db/db 41 $\pm 1 \%$, linagliptin $73 \pm 6 \%, p<0.05$ ). The enhanced response was maintained in the presence of TRAM-34+ apamin (ACh Rmax; db/db 23 $\pm 6 \%$, linagliptin 60 $\pm 6 \%, p<0.01$ ), ie, when the endothelium-dependent relaxation was mediated by NO. There was no evidence for a contribution from $\mathrm{K}_{\mathrm{Ca}}$ channel opening to responses under any conditions. Glimepiride had no effect on endothelium-dependent relaxation when given alone (ACh Rmax $38 \pm 3 \%$ ). The addition of linagliptin or vildagliptin to glimepiride did not significantly improve endothelium-dependent relaxation. All treatments caused some decrease in aortic superoxide production but the effect of linagliptin was significantly greater than glimepiride (linagliptin $534 \pm 60$ relative luminescence unit [RLU], glimepiride 1471 $\pm 265 \mathrm{RLU}, p<0.05$ ).

Conclusion: Linagliptin is superior to glimepiride in regard to the preservation of endothelium-dependent relaxation in the presence of hyperglycemia and the improvement in endothelial function in response to linagliptin treatment is associated with greater antioxidant activity compared to glimepiride.

Keywords: diabetes, DPP-4 inhibitor, endothelium-dependent relaxation, glimepiride, linagliptin, reactive oxygen species

\section{Introduction}

Type-4 dipeptidyl peptidase (DPP-4) inhibitors are used to attenuate hyperglycemia in type 2 diabetes. There is growing evidence that this class of drugs may have 
additional effects on cardiovascular function independently of those on plasma glucose that may be viewed as beneficial. ${ }^{1,2}$ We demonstrated previously that the DPP-4 inhibitor, linagliptin, exerts an acute antioxidant effect in vitro, a property not shared by two other DPP-4 inhibitors, vildagliptin and sitagliptin. ${ }^{3}$ It has been shown that the DPP-4 inhibitor teneligliptin exerts antioxidant activity in human umbilical vein endothelial cells. ${ }^{4}$ Linagliptin also improves endothelium-dependent relaxation of mesenteric arteries that have been impaired in the presence of high glucose-induced oxidative stress. ${ }^{3}$ Furthermore, in rats with streptozotocin-induced type 1 diabetes, exposure to linagliptin appeared to block diabetes-induced impairment of endothelial function. ${ }^{5}$ Notably, the effect on the endothelium occurred in the absence of any observable linagliptin-induced reduction in plasma glucose concentration. The apparent effect of linagliptin to improve endothelial function, by a mechanism that is independent of any action on glucose concentration, is supported by observations that linagliptin treatment improves impaired endothelial function in mice with elevated lipid levels or where endothelium-dependent relaxation was impaired by sodium arsenite-induced oxidative stress. ${ }^{6}$ These findings are consistent with observations in diabetic patients, where DPP-4 inhibitors appear to improve endothelium-dependent relaxation in terms of increased flow-mediated dilatation of the brachial artery although it should be noted that not all studies with DPP-4 inhibitors have confirmed this effect. $^{7-9}$

The sulfonylureas are another group of frequently used anti-diabetic agents. In contrast to DPP-4 inhibitors, there is no clinical evidence that sulfonylureas, such as glimepiride, have any direct effect on endothelial function ${ }^{10-12}$ despite some pre-clinical evidence supporting increased endothelial nitric oxide synthase (eNOS) activity with glimepiride $^{13,14}$ and apparent antioxidant properties in patients with type 2 diabetes. ${ }^{15}$ In the treatment of type 2 diabetes, the sulfonylureas and DPP-4 inhibitors may be used either alone or in combination ${ }^{16}$ but to the best of our knowledge, there are no previous reports of the effect on endothelial function of the combined use of these compounds.

The aim of this in vitro study, performed in $a \mathrm{db} / \mathrm{db}$ mouse model of type 2 diabetes, was to investigate how two DPP-4 inhibitors, linagliptin and vildagliptin, impact on production of reactive oxygen species (ROS) and endothelial function when administered in combination with the sulphonylurea, glimepiride. Further, given the ongoing CAROLINA (Cardiovascular outcome trial of linagliptin versus glimepiride in type 2 diabetes ${ }^{17}$ ) clinical trial, it was of interest to also directly compare the effects of glimepiride and linagliptin when given alone.

\section{Materials and methods}

\section{Animals}

Female $\mathrm{db} / \mathrm{db}$ mice (aged 5-6 weeks) were assigned randomly to one of five active study groups where they received: no treatment $(\mathrm{n}=12)$; glimepiride alone from weeks 1-6 ( $\mathrm{n}=12)$; glimepiride from weeks 1-6 with vildagliptin from weeks 4-6 $(n=11)$; glimepiride from weeks 1-6 with linagliptin from weeks 4-6 ( $\mathrm{n}=11)$; or linagliptin alone from weeks 1-6 $(\mathrm{n}=12)$. Doses employed were: glimepiride ( $2 \mathrm{mg} / \mathrm{kg}$ po per day); vildagliptin ( $3 \mathrm{mg} / \mathrm{kg}$ po per day); and linagliptin ( $3 \mathrm{mg} / \mathrm{kg}$ po per day). A sixth group of untreated C57/BL6 mice served as non-diabetic controls $(n=10)$. The dose of glimepiride used has been shown to engender effective glucose control in mice fed a high-fat $\operatorname{diet}^{18}$ and linagliptin and vildagliptin have been demonstrated to effectively lower plasma DPP-4 activity at $3 \mathrm{mg} / \mathrm{kg} /$ day. ${ }^{19}$

All animals underwent sampling for determination of plasma glucose concentration, type-1 glucagon-like peptide (GLP-1) and glycated hemoglobin $\left(\mathrm{Hb}_{\mathrm{Alc}}\right)$ before treatment was commenced with blood obtained from the tail vein. The mice were not fasted prior to blood collection. Measurements were repeated at Week 3 and at the end of the period of experimentation, prior to euthanasia by carbon dioxide asphyxiation. Final blood samples were obtained from the left ventricle by cardiac puncture and glucose concentration measured using a one-touch glucometer (Roche, Sydney, NSW, Australia). $\mathrm{Hb}_{\mathrm{Alc}}$ was measured by immunoassay using an $\mathrm{A} 1 \mathrm{cNow}{ }^{\circledR}$ kit (POCD, Sydney, NSW, Australia) and GLP-1 was measured using a commercial enzymelinked immunosorbent assay (Merck Millipore, USA).

All procedures involved were approved by the Animal Experimentation Ethics Committees of RMIT University (AEC no. 1609) and conform to the Australian National Health and Medical Research Council code of practice for the care and use of animals for scientific purposes.

\section{Myograph experiments}

Thoracic aortae were dissected and placed in Krebs bicarbonate solution $(118 \mathrm{mmol} / \mathrm{L} \mathrm{NaCl}, 4.7 \mathrm{mmol} / \mathrm{L} \mathrm{KCl}, 1.18$ $\mathrm{mmol} / \mathrm{L} \quad \mathrm{MgSO}_{4}, \quad 1.2 \mathrm{mmol} / \mathrm{L} \quad \mathrm{KH}_{2} \mathrm{PO}_{4}, 25 \mathrm{mmol} / \mathrm{L}$ $\mathrm{NaHCO}_{3}, 11.1 \mathrm{mmol} / \mathrm{L}$ D-glucose and $2.5 \mathrm{mmol} / \mathrm{L} \mathrm{CaCl}_{2}$, 
$\mathrm{pH}$ 7.4), aerated with $5 \%$ carbon dioxide $\left(\mathrm{CO}_{2}\right)$ in oxygen $\left(\mathrm{O}_{2}\right)$ and maintained at $37^{\circ} \mathrm{C}$. Fat and connective tissue were cleared from the arterial tissue, which was then cut into long ring segments $(2-3 \mathrm{~mm})$. Aortic rings were mounted in a myograph (model 610M, Danish Myo Technology, Aarhus, Denmark) containing Krebs solution containing the cyclooxygenase inhibitor indomethacin (10 $\mu \mathrm{M})$. After the rings were mounted, they were allowed to stabilize for a period of $15-30$ mins while under a tension of $5 \mathrm{mN}$. All experiments were conducted at $37^{\circ} \mathrm{C}$ in the Krebs solution aerated with carbogen $\left(95 \% \mathrm{O}_{2}\right.$ and $5 \%$ $\mathrm{CO}_{2}$ ). Once resting tension had stabilized, the thromboxane receptor agonist $\mathrm{U} 46619(10 \mu \mathrm{M})$ was added for 20 mins to induce maximum contraction. To assess the integrity of the endothelium, the aortic rings were pre-contracted to $\sim 50 \%$ of maximum response with the thromboxane receptor agonist U46619 (1-10 nM) and a single concentration of acetylcholine $(10 \mu \mathrm{M})$ was used to relax the artery rings. The endothelium of individual ring preparations were considered to be functionally intact where acetylcholine-induced relaxation was greater than $70 \%$ of the pre-contracted tone. After further washouts and return to basal tension, arteries were again pre-contracted to $\sim 50 \%$ of maximum response using the $\alpha$-adrenoceptor agonist, cirazoline $(0.01-0.1 \mu \mathrm{M})$. The effect of the treatment on relaxant responses was examined by constructing cumulative concentrationresponse curves to acetylcholine $(0.1 \mathrm{nM}-10 \mu \mathrm{M})$. In addition, responses to acetylcholine were examined after incubation for 20 mins with different combinations of: N-nitroL-arginine (L-NNA, $100 \mu \mathrm{mol} / \mathrm{L}$ ), a non-selective nitric oxide synthase inhibitor; $1 \mathrm{H}-[1,2,4]$ oxadiazolo[4,3-a]quinoxalin-1-one (ODQ, $10 \mu \mathrm{mol} / \mathrm{L}$ ), an inhibitor of soluble guanylate cyclase (sGC); 1-[(2-chlorophenyl) (diphenyl) methyl]-1H-pyrazole (TRAM-34, $1 \mu \mathrm{M}$ ), a selective inhibitor of the intermediate-conductance calcium-activated potassium channel $\left(\mathrm{IK}_{\mathrm{Ca}}\right)$; and apamin $(1 \mu \mathrm{M})$, a smallconductance calcium-activated potassium channel $\left(\mathrm{SK}_{\mathrm{Ca}}\right)$ inhibitor.

\section{Vascular superoxide}

Production of superoxide anion in aortic rings was measured using L-012 chemiluminescence as described previously ${ }^{20}$ with the following modifications. Aortic segments were cleared of fat and connective tissue and cut into segments $(2-3 \mathrm{~mm})$ which were incubated in cell culture plates at $37^{\circ} \mathrm{C}$ for 30 mins in Krebs-HEPES buffer.

A single aortic segment was added to each well of a 96-well optiplate with Krebs-HEPES buffer $(300 \mathrm{~mL})$, containing L-012 (100 mM, Wako Pure Chemicals, Osaka, Japan) and the appropriate investigational treatments before loading into a Polarstar Optima plate reader (BMG Labtech, Melbourne, VIC, Australia) to measure photon emission at $37^{\circ} \mathrm{C}$. Background readings without aortic segments were taken first. Superoxide production was quantified by subtracting the final reading from the background reading and counts were then taken as arbitrary units of superoxide production and expressed as a ratio to dry tissue mass (AU/mg dry tissue).

\section{Drugs}

All drugs were purchased from Sigma-Aldrich (Australia) except for linagliptin which was a gift from BoehringerIngelheim. Stock solutions $(10 \mathrm{mg} / \mathrm{mL})$ of glimepiride, linagliptin and vildagliptin were prepared in dimethyl sulfoxide (DMSO) and stored at $-20^{\circ} \mathrm{C}$. For administration by gavage, these drugs were further diluted in $1 \% \mathrm{w} / \mathrm{v}$ methylcellulose. L-NNA was dissolved in $0.1 \mathrm{M}$ sodium bicarbonate, ODQ and TRAM-34 were dissolved in dimethyl sulfoxide and apamin was dissolved in distilled water.

\section{Statistical analysis}

Results were compared by one-way or two-way analysis of variance (ANOVA) with a post hoc Dunnett's or Sidak's test using Graphpad Prism (Version 7, GraphPad Software, San Diego, USA). Comparisons providing $p$-values of less than 0.05 were considered as indicating statistical significance.

\section{Results}

\section{Body weight, blood glucose and $\mathrm{Hb}_{\mathrm{Alc}}$}

Changes in mean body weight, blood glucose concentration and $\mathrm{Hb}_{\mathrm{Alc}}$ in the six different groups over the 6-week study period are shown in Figure 1. Mean body weights of the $\mathrm{db} / \mathrm{db}$ mice were significantly higher than that in the C57/BL6 mice (Figure 1A, $p<0.001$ ). All mean (SEM) body weights increased during the study but there was no significant impact of any of the investigatory agents on weight. Mean blood glucose concentration and $\mathrm{Hb}_{\mathrm{Alc}}$ in the $\mathrm{db} / \mathrm{db}$ mice were significantly higher than in the C57/BL6 mice over the course of the study $(p<0.001$ in both cases). Mean blood glucose levels and $\mathrm{Hb}_{\mathrm{Alc}}$ increased in all $\mathrm{db} / \mathrm{db}$ mice study groups over the 6-week study but there was no significant impact of any of the investigatory agents on either parameter (Figure 1B). 


\section{A}

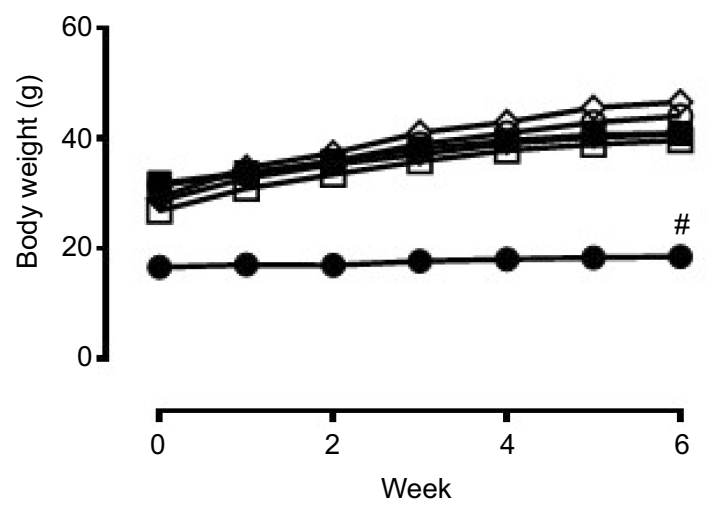

B

C
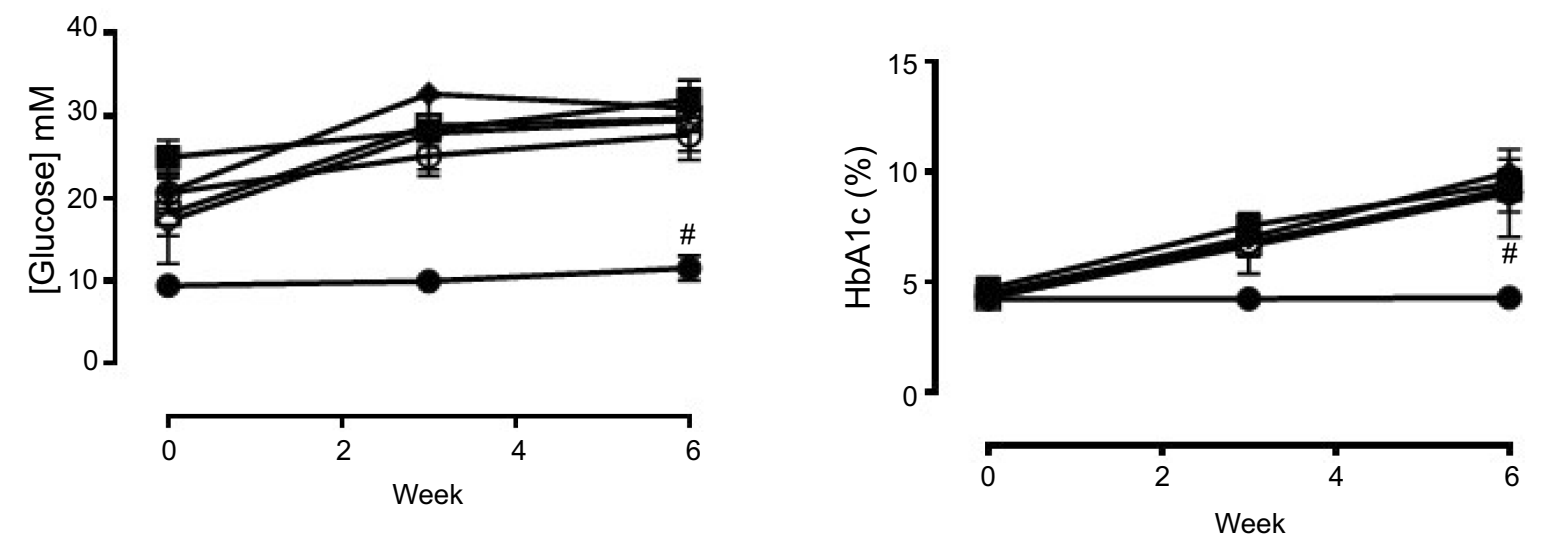

Figure I Body weights $(\mathbf{A})$, blood glucose concentration $(\mathbf{B})$ and $\mathrm{Hb}_{\mathrm{Alc}}(\mathbf{C})$ in the six different groups of mice over the 6-week treatment period. All parameters were significantly higher in $\mathrm{db} / \mathrm{db}$ compared to C57/BL6 mice and none of the treatments had any effect. Data are expressed as means \pm standard error (SEM). ${ }^{\#}<0.00 \mathrm{I}$ compared to $\mathrm{db} / \mathrm{db}$ over the 6-week treatment period, two-way ANOVA and Dunnett's test, $\mathrm{n}=10-12$.

Abbreviation: ANOVA, analysis of variance.

During the study, mean blood glucose levels increased slightly whereas mean $\mathrm{Hb}_{\mathrm{Alc}}$ levels remained stable in the C57/BL6 mice (Figure 1C). Mean plasma GLP-1 concentrations measured at the end of the 6-week study period were significantly higher in the vehicle-treated $\mathrm{db} / \mathrm{db}$ mice compared to the vehicle-treated C57/BL6 mice (Figure 2). None of the treatments affected significantly the GLP-1 concentrations in $\mathrm{db} / \mathrm{db}$ mice.

\section{Vascular superoxide}

Mean superoxide release from isolated aortic rings dissected from vehicle-treated $\mathrm{db} / \mathrm{db}$ mice and measured using the L012 luminescence assay was significantly higher than those from vehicle-treated C57/BL6 mice ( $p<0.05$; Figure 3). Pretreatment with glimepiride in the $\mathrm{db} / \mathrm{db}$ mice was associated with a significant reduction in mean aortic superoxide release (versus vehicle-treated $\mathrm{db} / \mathrm{db}$ mice) that was similar in both the absence and presence of vildagliptin co-administration
( $p<0.05$ in both cases). Pretreatment with linagliptin was also associated with a reduction in mean aortic superoxide release (versus vehicle-treated $\mathrm{db} / \mathrm{db}$ mice; $p<0.05$ ). Linagliptin, either alone or with glimepiride, caused a significantly greater reduction in superoxide compared to glimepiride, either alone or with vildagliptin.

\section{Myograph experiments}

Acetylcholine concentration response (relaxation \%) curves constructed for the aortae from animals from each of the six treatment groups are shown in Figures 4 and 5. Mean acetylcholine sensitivity $\left(\mathrm{pEC}_{50}\right.$ ) profile was similar in all six groups (Table 1). The mean maximum acetylcholine relaxation response in the $\mathrm{db} / \mathrm{db}$ mice was significantly lower (approx. $50 \%$ ) than that seen in the C57/BL6 mice (Figure 4A). Mean maximum relaxation in aortic rings from $\mathrm{db} / \mathrm{db}$ animals pretreated with glimepiride was similar to that in vehicle-treated $\mathrm{db} / \mathrm{db}$ mice. In contrast, mean maximum relaxation was greater 


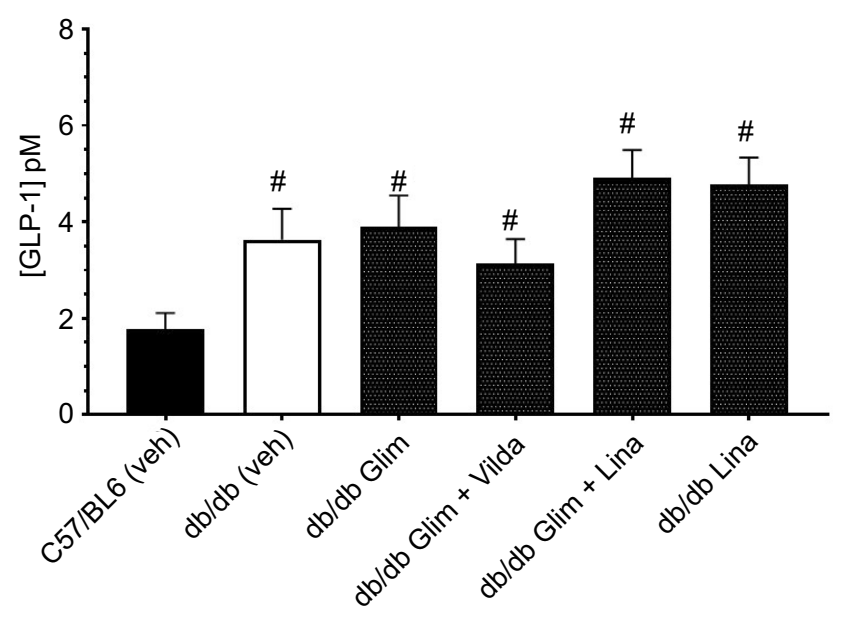

Figure 2 The plasma concentration of glucagon-like peptide I (GLP-I) was significantly lower in C57/BL6 compared to db/db mice. GLP-I concentration was not affected by any of the treatments. Data are expressed as mean \pm SEM. " Significantly different compared to C57/BL6 (veh), $p<0.05$ one-way ANOVA and Sidak's test, $n=10-12$.

Abbreviation: ANOVA, analysis of variance.

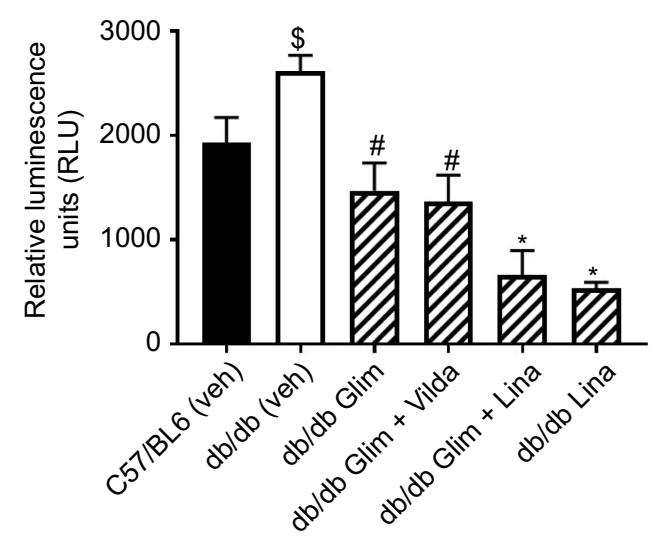

Figure 3 Measurement of superoxide generated in mouse aortae using L- 012 enhanced chemiluminescence from the six groups. Data are expressed as mean \pm SEM Notes: \$Significantly different to C57/BL6 (veh), $p<0.05$, one-way ANOVA, Sidak's multiple comparisons test. "Significantly different to $\mathrm{db} / \mathrm{db}, p<0.05$, one-way ANOVA, Sidak's multiple comparisons test. *Significantly different to $\mathrm{db} / \mathrm{db}$ (veh) and $\mathrm{db} / \mathrm{db}+$ glimepiride, $p<0.05$, one-way ANOVA, Sidak's multiple comparisons test. $\mathrm{n}=10-12$.

Abbreviation: ANOVA, analysis of variance.

in animals treated with glimepiride in combination with either vildagliptin or linagliptin (Figure 5), though the differences from the vehicle-treated group did not achieve statistical significance (Table 1). However, mean maximum acetylcholine relaxation response in the $\mathrm{db} / \mathrm{db}$ mice pre-treated with linagliptin alone was significantly higher than that in vehicle-treated $\mathrm{db} / \mathrm{db}$ mice $(p<0.05)$ and similar to that seen in the C57/BL6 mice (Figure 4A, Table 1).

The effect of the various treatments on the NO-mediated component of the endothelium-dependent aortic relaxation was investigated by constructing acetylcholine concentration
Control
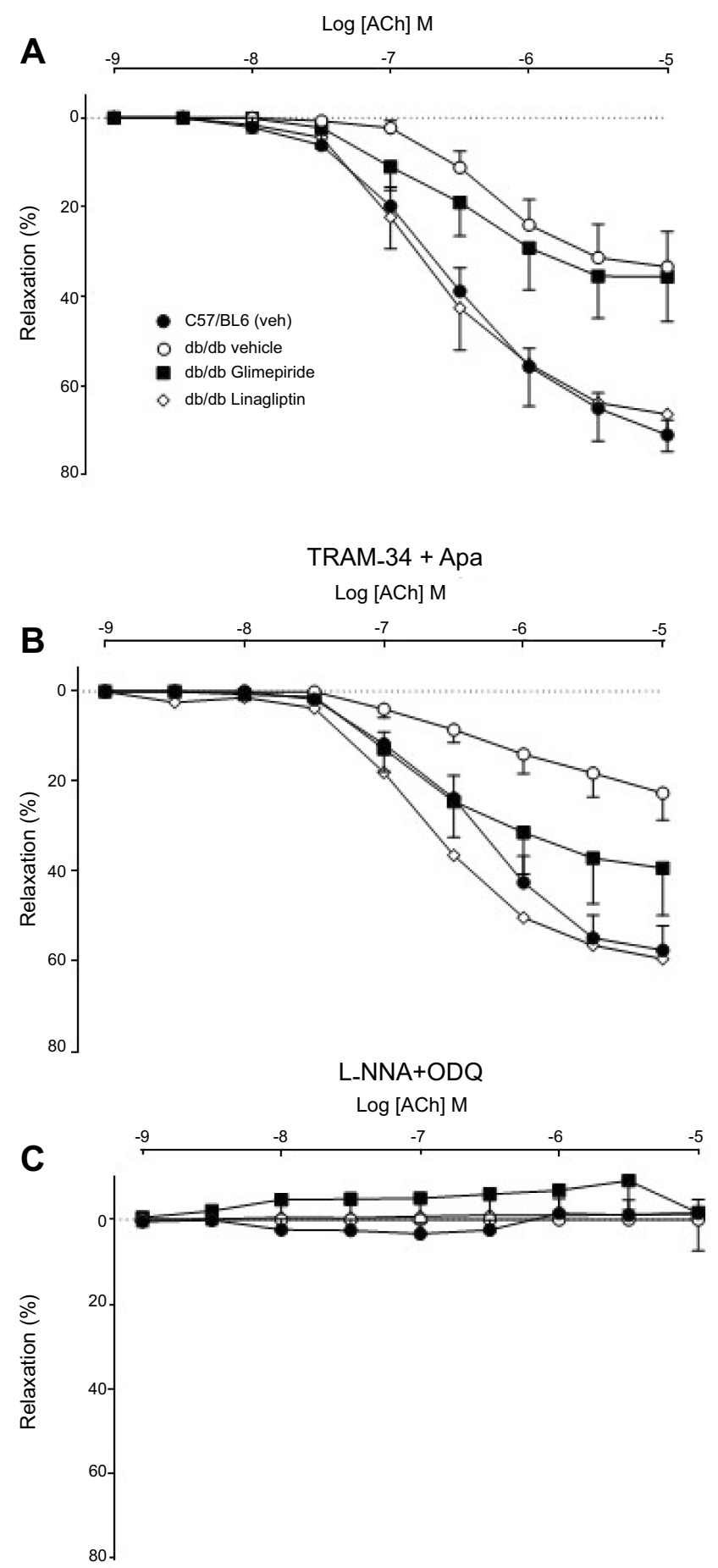

Figure 4 Concentration response curves to ACh aortae from C57/BL6 mice and $\mathrm{db} / \mathrm{db}$ mice treated with vehicle, glimepiride or linagliptin for 6 weeks. Responses to ACh were tested in the absence (A) or presence of TRAM-34 plus apamin (B) to inhibit $\mathrm{IK}_{\mathrm{Ca}}$ and $\mathrm{SK}_{\mathrm{Ca}}$, respectively, or N-nitro L-arginine (L-NNA) plus $\mathrm{IH}-[1,2,4]$ oxadiazolo[4,3-a]quinoxalin-I-one (ODQ) (C) to block nitric oxide synthase and guanylate cyclase, respectively. Calculated values for sensitivity $\left(\mathrm{pEC}_{50}\right)$ and maximum response $\left(R_{\max }\right)$ derived from these data are shown in Table $\mathrm{I}$.

response curves in the presence of TRAM-34 and apamin to inhibit $\mathrm{IK}_{\mathrm{Ca}^{-}}$and $\mathrm{SK}_{\mathrm{Ca}}$-induced relaxation, respectively 

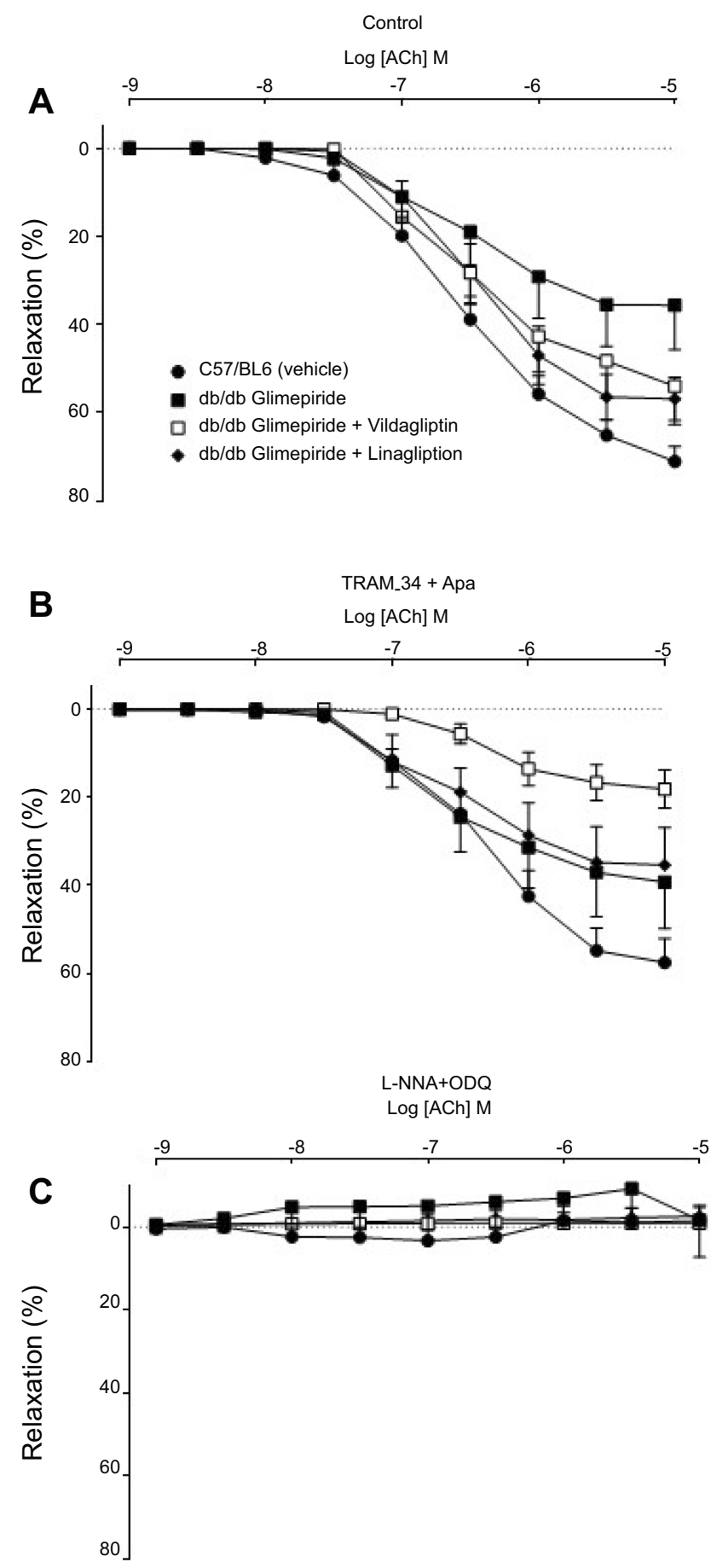

Figure 5 Concentration response curves to $\mathrm{ACh}$ in aortae from C57/BL6 mice and $\mathrm{db} / \mathrm{db}$ mice treated with vehicle or glimepiride either alone or in combination with vildagliptin or linagliptin. Responses to $A C h$ were tested in the absence (A) or presence of TRAM-34 plus apamin (B) to inhibit $\mathrm{IK}_{\mathrm{Ca}_{\mathrm{a}}}$ and $\mathrm{SK}_{\mathrm{C}_{\mathrm{a}}}$, respectively, or N-nitro L-arginine (L-NNA) plus IH-[I,2,4]oxadiazolo[4,3-a]quinoxalinI-one (ODQ) (C) to block nitric oxide synthase and guanylate cyclase, respectively. Calculated values for sensitivity $\left(\mathrm{pEC}_{50}\right)$ and maximum response $\left(\mathrm{R}_{\max }\right)$ derived from these data are shown in Table I.

(Figures 4B and 5B). Acetylcholine-induced maximum relaxation in tissue from vehicle $\mathrm{db} / \mathrm{db}$ mice was significantly lower than that seen in C57/BL6 mice whereas estimates of

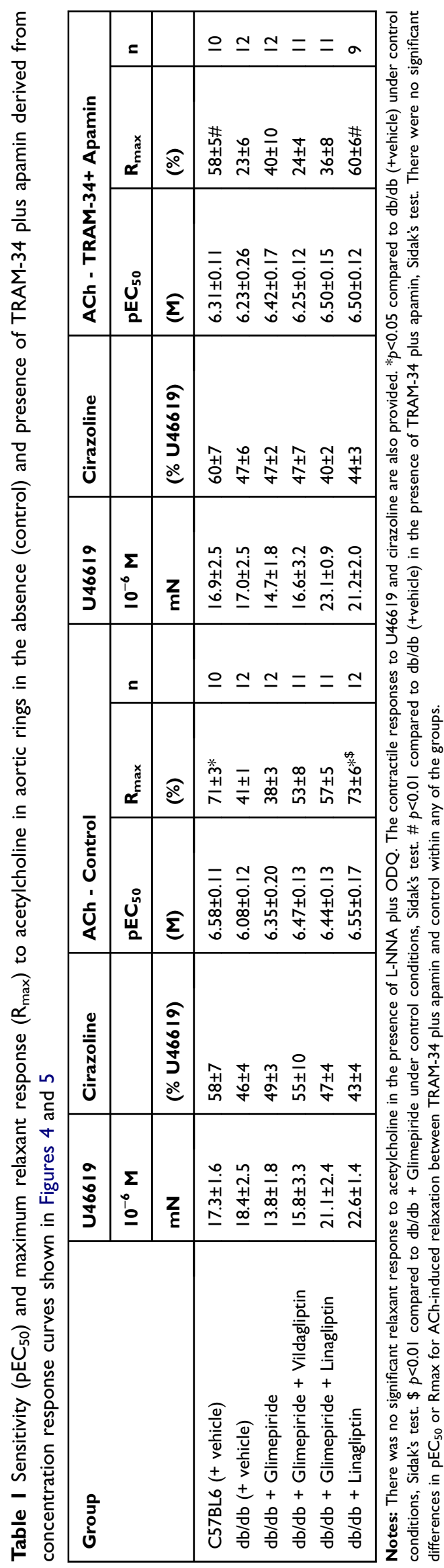


sensitivity $\left(\mathrm{pEC}_{50}\right)$ were similar (Table 1$)$. The acetylcholine response profile in the $\mathrm{db} / \mathrm{db}$ mice exposed to glimepiride was similar to that of vehicle-treated $\mathrm{db} / \mathrm{db}$ mice. In contrast, maximal aortic relaxation was significantly greater when the mice were treated with linagliptin alone (Table 1). The addition of linagliptin or vildagliptin to glimepiride did not significantly affect the response to acetylcholine. Acetylcholine-induced relaxation was abolished across the groups by incubation of aortic tissue with L-NNA and ODQ, added to inhibit nitric oxide synthase (NOS) and soluble guanylate cyclase, respectively (Figures 4C and 5C).

\section{Discussion}

Our in vivo study demonstrated an effect of linagliptin treatment (3 mg/kg po per day, 6 weeks) in female $\mathrm{db} / \mathrm{db}$ mice on acetylcholine-induced endothelium-dependent relaxation of isolated thoracic aorta. Exposure to linagliptin appeared to redress the difference between these and the control C57/BL6 mice that has been reported previously. $^{21,22}$ The apparent effect of linagliptin on relaxation was markedly different from that of the sulfonylurea glimepiride administered under similar conditions. The differences in endothelium-dependent relaxation were less marked when mice were pretreated with linagliptin, or a second DPP-4 inhibitor vildagliptin, for a shorter period (3 weeks) in combination with glimepiride (6 weeks) and failed to achieve statistical significance versus relaxation in vehicle-treated control $\mathrm{db} / \mathrm{db}$ mice. Comparison of the different acetylcholine-induced endothelium-dependent relaxation profiles in the presence of selective inhibitors of eNOS, guanylate cyclase, $\mathrm{SK}_{\mathrm{Ca}}$ and $\mathrm{IK}_{\mathrm{Ca}}$ channels indicated that the impact of linagliptin on endotheliumdependent relaxation was mediated through an effect on NO activity that occurs in the absence of any effect on endothelium-dependent hyperpolarisation.

In comparison to the control mice, the female $\mathrm{db} / \mathrm{db}$ mice used in this study had significantly greater body weight, plasma glucose, HbA1c and plasma GLP-1 as expected in this model of type 2 diabetes. Interestingly none of the treatments, ie, glimepiride, DPP-4 inhibitors or their combination, had any effect on these parameters. This is similar to a previous report from Sharkovska et $\mathrm{al}^{23}$ who found that linagliptin at the same dose failed to improve glucose control in male $\mathrm{db} / \mathrm{db}$ mice. The dose of linagliptin was considered adequate as that dose has been shown previously to be equally effective as a 10 -fold higher dose in the inhibition of DPP-4 activity. ${ }^{24}$ Nagakura et $\mathrm{al}^{25}$ found that whereas DPP-4 inhibitors were effective in young (6 weeks) $\mathrm{db} / \mathrm{db}$ mice, they lost efficacy as the mice aged indicating that, as in the present study, in this model of $\beta$ cell failure and high insulin resistance, the treatments did not effectively improve glucose control and our study suggests this is so for females as well as males. Despite this, the DPP-4 inhibitors did show evidence of improved endothelial function as we have previously reported in a model of type 1 diabetes. ${ }^{5}$

The capacity of linagliptin to redress the deficient endothelium-dependent relaxation reported in $\mathrm{db} / \mathrm{db}$ mice appeared to be associated with a significant reduction in the generation of superoxide by the aortae. Vascular superoxide production was significantly elevated in aortae from the $\mathrm{db} /$ $\mathrm{db}$ mice compared to the control C57/BL6 mice, an observation that was consistent with other reports in a variety of animal models of both type 1 and type 2 diabetes. $^{26,27}$ We previously reported how treatment with linagliptin for 6 weeks significantly reduces vascular superoxide production in a model of type 1 diabetes (ie, streptozotocin-treated rats). ${ }^{5}$ In this case, superoxide levels were also lower when mice were treated with linagliptin for a shorter period (3 weeks) in combination with glimepiride than those in $\mathrm{db} / \mathrm{db}$ mice treated with vehicle or glimepiride alone. The apparent antioxidant activity of linagliptin is consistent with previously reported attenuation of superoxide levels in rat-isolated mesenteric arteries, both under control conditions and in the presence of high glucose concentrations $(40 \mathrm{mM}) .^{3}$ These findings suggest that linagliptin may scavenge oxygen radicals. This property may not be a group DPP-4 inhibitor effect, as in our previous study we found an absence of effect by vildagliptin or sitagliptin. ${ }^{3}$ In the present study, the antioxidant action of vidagliptin plus glimepiride was not different to glimepiride alone and was significantly less than linagliptin with or without glimepiride. It seems likely also that the acute in vivo antioxidant activity of linagliptin is through a reduction, at least in part, of superoxide synthesis since it was associated with increased expression of eNOS as a dimer, which in its coupled form favors synthesis of NO rather than superoxide. ${ }^{5}$ Linagliptin was also associated with a significant decrease in the expression of $\mathrm{NOX} 2$, another important source of vascular superoxide. ${ }^{28}$ The evidence implies therefore that linagliptin serves to reduce both the synthesis and activity of superoxide, two possible mechanisms that might improve endothelium-derived NO activity. In contrast, glimepiride alone or in combination with vildagliptin pretreatment impacted significantly less on the diabetesinduced elevation in superoxide. 
It is well known that the activity of endothelium-derived nitric oxide is impaired by oxidative stress, including that caused by diabetes. In the present study, which uses mouse thoracic aorta, the evidence points to the endothelium-dependent relaxation being mediated entirely by nitric oxide as the responses to acetylcholine were abolished by the combined inhibition of NOS by L-NNA and guanylate cyclase by ODQ. The findings suggest that NO-mediated relaxation is impaired in arteries from the diabetic $\mathrm{db} / \mathrm{db}$ mice and that normalization of the relaxation response by linagliptin is maintained in the presence of TRAM-34 and apamin, inhibitors of $\mathrm{IK}_{\mathrm{Ca}}$ and $\mathrm{SK}_{\mathrm{Ca}}$, respectively, which inhibit endothelium-dependent hyperpolarisation. It is worth noting that evidence from experiments conducted in the small mesenteric arteries taken from streptozotocin-treated rats suggests that linagliptin may also enhance relaxation through hyperpolarisation as well as NO-mediated mechanisms ${ }^{5}$ whereas in this study using a conductance artery we found that TRAM-34 plus apamin had no effect on ACh-induced relaxation indicating no contribution of hyperpolarization to endothelium-dependent relaxation. Whilst we have previously found that a contribution of potassium channel opening does contribute to endothelium-dependent relaxation of rat aortae in a model of type 1 diabetes, ${ }^{29}$ that was determined not to be the case in this type 2 diabetes model in mice.

It is noteworthy that our findings imply that the effect of linagliptin on aortic relaxation is independent of its actions on glucose metabolism. In the present work, linagliptin did not impact on blood concentrations of glucose or hemoglobin $\mathrm{Hb}_{\mathrm{Alc}}$, neither did it impact on body weight, as has been observed previously in type 1 diabetic rats. ${ }^{3}$ Similarly, it has been reported previously how linagliptin in non-obese diabetic mice, another model of type 1 diabetes, resulted in an improvement of endothelium-dependent relaxation, an effect that was accompanied by an increase in eNOS expression and a decrease in expression of caveolin- $1,{ }^{30}$ which inhibits eNOS activity. Previously, we have shown that linagliptin-induced improvement in endothelium-dependent relaxation is also accompanied by an increase in eNOS expression in mesenteric arteries from streptozotocin-treated rats. Taken together, the evidence appears to point to linagliptin possessing some property that enhances the synthesis of nitric oxide that is independent of any action it has on glucose homeostasis. Several clinical studies have made observations that suggest changes in endothelium-dependent relaxation in response to linagliptin. For example, researchers noted improvements in brachial artery flow-mediated dilatation (FMD) compared to metformin treatment alone when linagliptin was administered in addition to metformin to patients with type 2 diabetes. ${ }^{31}$ It has been suggested that the effect on relaxation may be a DPP4 class effect as both vildagliptin and sitagliptin have been shown to enhance endothelium-dependent relaxation in subjects with hyperglycemia. ${ }^{32,33}$ However, any relationship appears to not be straightforward. Treatment with linagliptin alone was reported not to affect FMD despite in one report being associated with improvements in microvascular function that were independent of any changes in glucose regulation. ${ }^{10}$ There are also reports in patients with type 2 diabetes where sitagliptin had no effect on FMD, ${ }^{7}$ and in another case even caused a deterioration in endothelial function.

Evidence from studies conducted with linagliptin in conditions where endothelial dysfunction is not caused by hyperglycemia seems to support the potential for linagliptin to have beneficial vascular actions, again independent of glucose homeostasis. For example, linagliptin improved endothelial dysfunction in aortae from rats exposed to sepsis $^{34}$ when oxidative stress was increased by administration of sodium arsenite. ${ }^{6}$ Linagliptin was also seen to improve endotheliumdependent relaxation in aortae from apolipoprotein-E-deficient mice, an effect that was accompanied by a decrease in oxidative stress and decreased development of atherosclerotic plaques. ${ }^{35}$ These observations indicate vasculoprotective actions of linagliptin that extend to other diseases involving oxidative stress, such as atherosclerosis.

In conclusion, unlike glimepiride, linagliptin displays vasculoprotective properties that result, at least in part, from its antioxidant activity. This property may be common to DPP-4 inhibitors but evidence from this and our earlier study ${ }^{5}$ suggests that linagliptin appears to be more effective at preserving endothelial function and reducing superoxide in comparison to other DPP-4 inhibitors.

\section{Acknowledgment}

This project was supported by funding from BoehringerIngelheim.

\section{Author contributions}

All authors contributed to data analysis, drafting and revising the article, gave final approval of the version to be published, and agree to be accountable for all aspects of the work.

\section{Disclosure}

TK is an employee of Boehringer Ingelheim. OLW was contracted by Boehringer Ingelheim for conduct of research, during the conduct of the study. The authors report no other conflicts of interest in this work. 


\section{References}

1. Aroor AR, Sowers JR, Jia G, DeMarco VG. Pleiotropic effects of the dipeptidylpeptidase-4 inhibitors on the cardiovascular system. Am J Physiol Heart Circ Physiol. 2014;307(4):H477-H492. doi:10.1152/ ajpheart.00209.2014

2. Ahmed HA, May DW, Fagan SC, Segar L. Vascular protection with dipeptidyl peptidase-IV inhibitors in diabetes: experimental and clinical therapeutics. Pharmacotherapy. 2015;35(3):277-297. doi:10.1002/ phar.1547

3. Salheen SM, Panchapakesan U, Pollock CA, Woodman OL. The DPP-4 inhibitor linagliptin and the GLP-1 receptor agonist exendin4 improve endothelium-dependent relaxation of rat mesenteric arteries in the presence of high glucose. Pharmacol Res. 2015;94:26-33. doi:10.1016/j.phrs.2015.02.003

4. Pujadas G, De Nigris V, Prattichizzo F, La Sala L, Testa R, Ceriello A. The dipeptidyl peptidase-4 (DPP-4) inhibitor teneligliptin functions as antioxidant on human endothelial cells exposed to chronic hyperglycemia and metabolic high-glucose memory. Endocrine. 2017;56(3):509-520. doi:10.1007/s12020-016-1052-0

5. Salheen SM, Panchapakesan U, Pollock CA, Woodman OL. The dipeptidyl peptidase-4 inhibitor linagliptin preserves endothelial function in mesenteric arteries from Type 1 diabetic rats without decreasing plasma glucose. PLoS One. 2015;10(11):e0143941. doi:10.1371/journal.pone.0143941

6. Jyoti U, Kansal SK, Kumar P, Goyal S. Possible vasculoprotective role of linagliptin against sodium arsenite-induced vascular endothelial dysfunction. Naunyn Schmiedebergs Arch Pharmacol. 2016;389 (2):167-175. doi:10.1007/s00210-015-1184-4

7. Widlansky ME, Puppala VK, Suboc TM, et al. Impact of DPP-4 inhibition on acute and chronic endothelial function in humans with type 2 diabetes on background metformin therapy. Vasc Med 2017;22(3):189-196. doi:10.1177/1358863X16681486

8. Ayaori M, Iwakami N, Uto-Kondo H, et al. Dipeptidyl peptidase-4 inhibitors attenuate endothelial function as evaluated by flowmediated vasodilatation in type 2 diabetic patients. $J$ Am Heart Assoc. 2013;2(1):e003277. doi:10.1161/JAHA.112.003277

9. Kim G, Oh S, Jin SM, Hur KY, Kim JH, Lee MK. The efficacy and safety of adding either vildagliptin or glimepiride to ongoing metformin therapy in patients with type 2 diabetes mellitus. Expert Opin Pharmacother. 2017;18(12):1179-1186. doi:10.1080/ 14656566.2017.1353080

10. Jax T, Stirban A, Terjung A, et al. A randomised, active- and placebocontrolled, three-period crossover trial to investigate short-term effects of the dipeptidyl peptidase-4 inhibitor linagliptin on macroand microvascular endothelial function in type 2 diabetes. Cardiovasc Diabetol. 2017;16(1):13. doi:10.1186/s12933-017-0624-5

11. Machado HA, Vieira M, Cunha MR, et al. Metformin, but not glimepiride, improves carotid artery diameter and blood flow in patients with type 2 diabetes mellitus. Clinics (Sao Paulo). 2012;67 (7):711-717. doi:10.6061/clinics/2012(07)03

12. Nomoto H, Miyoshi H, Furumoto T, et al. A randomized controlled trial comparing the effects of sitagliptin and glimepiride on endothelial function and metabolic parameters: Sapporo Athero-Incretin Study 1 (SAIS1). PLoS One. 2016;11(10):e0164255. doi:10.1371/ journal.pone. 0164255

13. Jojima T, Suzuki K, Hirama N, Uchida K, Hattori Y. Glimepiride upregulates eNOS activity and inhibits cytokine-induced NF-kappaB activation through a phosphoinoside 3-kinase-Akt-dependent pathway. Diabetes Obes Metab. 2009;11(2):143-149. doi:10.1111/ j.1463-1326.2008.00923.x
14. Ma P, Gu B, Xiong W, et al. Glimepiride promotes osteogenic differentiation in rat osteoblasts via the PI3K/Akt/eNOS pathway in a high glucose microenvironment. PLoS One. 2014;9(11):e112243. doi:10.1371/journal.pone. 0112243

15. Nakamura I, Oyama J, Komoda H, et al. Possible effects of glimepiride beyond glycemic control in patients with type 2 diabetes: a preliminary report. Cardiovasc Diabetol. 2014;13:15. doi:10.1186/ 1475-2840-13-80

16. Garber AJ, Abrahamson MJ, Barzilay JI, et al. Consensus statement by the American Association of Clinical Endocrinologists and American College of Endocrinology on the comprehensive Type 2 diabetes management algorithm - 2017 executive summary. Endocr Pract. 2017;23(2):207-238. doi:10.4158/EP161682.CS

17. Marx N, Rosenstock J, Kahn SE, et al. Design and baseline characteristics of the CARdiovascular outcome trial of LINAgliptin versus glimepiride in Type 2 diabetes (CAROLINA (R)). Diabetes Vasc Dis Res. 2015;12(3):164-174. doi:10.1177/ 1479164115570301

18. Darsalia V, Ortsater H, Olverling A, et al. The DPP-4 inhibitor linagliptin counteracts stroke in the normal and diabetic mouse brain: a comparison with glimepiride. Diabetes. 2013;62(4):12891296. doi:10.2337/db12-0988

19. Thomas L, Eckhardt M, Langkopf E, Tadayyon M, Himmelsbach F, Mark M. (R)-8-(3-amino-piperidin-1-yl)-7-but-2-ynyl-3-methyl-1-(4methyl-quinazolin-2-ylm ethyl)-3,7-dihydro-purine-2,6-dione (BI 1356), a novel xanthine-based dipeptidyl peptidase 4 inhibitor, has a superior potency and longer duration of action compared with other dipeptidyl peptidase-4 inhibitors. J Pharmacol Exp Ther. 2008;325 (1):175-182. doi:10.1124/jpet.107.135723

20. Miller AA, Drummond GR, Schmidt HH, Sobey CG. NADPH oxidase activity and function are profoundly greater in cerebral versus systemic arteries. Circ Res. 2005;97(10):1055-1062. doi:10.1161/01. RES.0000189301.10217.87

21. Miike T, Kunishiro K, Kanda M, Azukizawa S, Kurahashi K, Shirahase $\mathrm{H}$. Impairment of endothelium-dependent ACh-induced relaxation in aorta of diabetic $\mathrm{db} / \mathrm{db}$ mice - possible dysfunction of receptor and/or receptor-G protein coupling. Naunyn Schmiedebergs Arch Pharmacol. 2008;377(4-6):401-410. doi:10.1007/s00210-008-0261-3

22. Cheang WS, Wong WT, Tian XY, et al. Endothelial nitric oxide synthase enhancer reduces oxidative stress and restores endothelial function in $\mathrm{db} / \mathrm{db}$ mice. Cardiovasc Res. 2011;92(2):267-275. doi: $10.1093 / \mathrm{cvr} / \mathrm{cvr} 233$

23. Sharkovska Y, Reichetzeder C, Alter M, et al. Blood pressure and glucose independent renoprotective effects of dipeptidyl peptidase-4 inhibition in a mouse model of type-2 diabetic nephropathy. $J$ Hypertens. 2014;32(11):2211-2223; discussion 2223. doi:10.1097/ HJH.0000000000000328

24. Kern M, Kloting N, Niessen HG, et al. Linagliptin improves insulin sensitivity and hepatic steatosis in diet-induced obesity. PLoS One. 2012;7(6):e38744. doi:10.1371/journal.pone.0038744

25. Nagakura T, Yasuda N, Yamazaki K, Ikuta $H$, Tanaka $I$. Enteroinsular axis of $\mathrm{db} / \mathrm{db}$ mice and efficacy of dipeptidyl peptidase IV inhibition. Metabolism. 2003;52(1):81-86. doi:10.1053/ meta.2003.50014

26. Bhatti JS, Bhatti GK, Reddy PH. Mitochondrial dysfunction and oxidative stress in metabolic disorders - a step towards mitochondria based therapeutic strategies. Biochim Biophys Acta Mol Basis Dis. 2017;1863(5):1066-1077. doi:10.1016/j.bbadis.2016.11.010

27. Leo CH, Hart JL, Woodman OL. 3',4'-Dihydroxyflavonol restores endothelium-dependent relaxation in small mesenteric artery from rats with type 1 and type2 diabetes. Eur $J$ Pharmacol. 2011;659:193-198. doi:10.1016/j.ejphar.2011.03.018 
28. Dikalov SI, Nazarewicz RR, Bikineyeva A, et al. Nox2-induced production of mitochondrial superoxide in angiotensin II-mediated endothelial oxidative stress and hypertension. Antioxid Redox Signal. 2014;20(2):281-294. doi:10.1089/ars.2012.4918

29. Malakul W, Thirawarapan S, Suvitayavat W, Woodman OL. Type 1 diabetes and hypercholesterolaemia reveal the contribution of endothelium-derived hyperpolarizing factor to endothelium-dependent relaxation of the rat aorta. Clinical Exp Pharmacol Physiol. 2008;35(2):192-200.

30. Vellecco V, Mitidieri E, Gargiulo A, et al. Vascular effects of linagliptin in non-obese diabetic mice are glucose-independent and involve positive modulation of the endothelial nitric oxide synthase (eNOS)/caveolin-1 (CAV-1) pathway. Diabetes Obes Metab. 2016;18 (12):1236-1243. doi:10.1111/dom.12750

31. Shigiyama F, Kumashiro N, Miyagi M, et al. Linagliptin improves endothelial function in patients with type 2 diabetes: a randomized study of linagliptin effectiveness on endothelial function. $J$ Diabetes Investig. 2017;8(3):330-340. doi:10.1111/jdi.12587
32. Kubota Y, Miyamoto M, Takagi G, et al. The dipeptidyl peptidase-4 inhibitor sitagliptin improves vascular endothelial function in type 2 diabetes. J Korean Med Sci. 2012;27(11):1364-1370. doi:10.3346/ jkms.2012.27.11.1364

33. van Poppel PC, Netea MG, Smits P, Tack CJ. Vildagliptin improves endothelium-dependent vasodilatation in type 2 diabetes. Diabetes Care. 2011;34(9):2072-2077. doi:10.2337/dc10-2421

34. Kroller-Schon S, Knorr M, Hausding M, et al. Glucose-independent improvement of vascular dysfunction in experimental sepsis by dipeptidyl-peptidase 4 inhibition. Cardiovasc Res. 2012;96(1):140149. doi:10.1093/cvr/cvs246

35. Salim HM, Fukuda D, Higashikuni Y, et al. Dipeptidyl peptidase-4 inhibitor, linagliptin, ameliorates endothelial dysfunction and atherogenesis in normoglycemic apolipoprotein-E deficient mice. Vascul Pharmacol. 2016;79:16-23. doi:10.1016/j.vph.2015. 08.011

Diabetes, Metabolic Syndrome and Obesity: Targets and Therapy

\section{Dovepress}

\section{Publish your work in this journal}

Diabetes, Metabolic Syndrome and Obesity: Targets and Therapy is an international, peer-reviewed open-access journal committed to the rapid publication of the latest laboratory and clinical findings in the fields of diabetes, metabolic syndrome and obesity research. Original research, review, case reports, hypothesis formation, expert opinion and commentaries are all considered for publication. The manuscript management system is completely online and includes a very quick and fair peer-review system, which is all easy to use. Visit http://www.dovepress.com/testimonials.php to read real quotes from published authors. 